\title{
Confiança organizacional: teste de um modelo
}

\author{
José Keating, Isabel Silva \& Ana Veloso \\ Escola de Psicologia - Universidade do Minho
}

\begin{abstract}
Apresentam-se os resultados da avaliação da validade do modelo de confiança organizacional de Mayer, Davis e Schoorman (1995), utilizando uma versão portuguesa desta escala com 903 pessoas. Os resultados iniciais mostram problemas com a escala de Confiança e com o próprio modelo teórico. É sugerida a necessidade de desenvolver estratégias diferentes para a medida da confiança organizacional
\end{abstract}

Palavras-chave: confiança organizacional; medida

\section{AGRADECIMENTOS}

Esta investigação foi financiada pela Fundação para a Ciência e Tecnologia (Projecto PTDC/PSI/74509/2006)

Os autores querem ainda agradecer aos estudantes do Mestrado em Psicologia da Universidade do Minho, nomeadamente a Ana Filipa Rodrigues, Ana Lúcia Rodrigues, Dina Rodrigues de Sousa, Célia Silva, Helena Pereira, Jennifer Belpalme, Mariana Moura, Rita Moreira, Rita Gonçalves e Sandrine Ribeiro pelo seu contributo na recolha de dados e nas discussões das suas implicações práticas.

\section{CONTACTO PARA CORRESPONDÊNCIA}

José Keating

keating@psi.uminho.pt

\section{CONFIANÇA: DEFINIÇÃO E NECESSIDADE TEÓRICA E PRÁTICA}

A confiança interpessoal tem sido definida de variadas formas por diversos autores, definições algo semelhantes, embora trazendo cada uma alguma clarificação a este conceito.

A confiança, na sua definição interpessoal, é simultaneamente familiar e estranha. Provavelmente já todos usamos a palavra com uma ideia clara do que queremos dizer, e provavelmente também já recorremos ao conceito para tentar descrever ou clarificar situações e relações. Mas as dificuldades começam se tentamos definir claramente o que entendemos por confiança, e como identificamos os fenómenos a ela associados. 
Um bom ponto de partida é a definição de Rousseau e colegas, segundo a qual a confiança é "um estado psicológico que inclui a disponibilidade para nos colocarmos numa situação de vulnerabilidade face a outra pessoa, baseada em expectativas positivas quanto às suas intenções e comportamentos" (Rousseau et al. 1998:395). Esta definição retoma definições anteriores (p.ex. Mayer, Davis e Schoorman, 1995) e inclui ainda uma especificação dos contextos em que se pode falar de confiança: a existência de risco e a interdependência entre as partes envolvidas são condições essenciais para que se possa falar de confiança numa relação. Onde não há risco ou onde não há interdependência, o conceito de confiança não será relevante, já que não se pode propriamente falar de vulnerabilidade, ou de expectativas relevantes face a outrem.

Risco e interdependência são noções essenciais para estender o conceito de confiança interpessoal assim definido ao contexto organizacional. Se olharmos as organizações como estruturas sociais que procuram garantir condições para a cooperação entre pessoas com interesses e motivações diferentes, e não necessariamente convergentes, os riscos envolvidos na pertença ou exclusão de tais estruturas, no reconhecimento dos diferentes contributos individuais e no acesso diferencial aos recursos gerados pela actividade da organização, para mencionar apenas alguns que parecem fundamentais, são consideráveis e reconhecidos. Estes riscos, juntamente com a interdependência entre as actividades dos membros da organização para atingir objectivos que, quaisquer que eles sejam, superam sempre a capacidade de realização individual, constituem condições suficientes para se procurar compreender a relevância do conceito de confiança na exploração dos processos psicológicos envolvidos na cooperação.

A ideia de confiança organizacional suscitou portanto um conjunto interessante de reflexões e hipóteses sobre o papel dos processos relacionados com a confiança no funcionamento das organizações. A que parece ser uma ideia essencial, comum a várias abordagens à confiança organizacional, baseia-se nesta ideia de que uma organização é uma forma de assegurar a cooperação entre pessoas com interesses diferentes: embora os sistemas de organização do poder e da autoridade assumam na maior parte dos casos o exercício de um poder unitário e coerente, a eficácia deste exercício de poder para assegurar a cooperação é cada vez melhor compreendida como resultante não da coerção pura e dura mas da aceitação autónoma e portanto condicional do exercício deste poder por parte daqueles cuja necessária cooperação se procura assegurar. 
Ora, é nesta aceitação do exercício do poder, e na previsibilidade dos comportamentos que dela resulta, que a confiança é uma dimensão essencial: onde não há confiança, os mecanismos de garantia, por exemplo contratos referentes a contrapartidas a receber pela execução adequada de um trabalho, são mais complexos, mais caros e eles próprios de resultados mais imprevisíveis. Aprofundando este exemplo, se cada avaliação do desempenho resulta num recurso e num processo judicial, os ganhos colectivos de realização que uma avaliação do desempenho poderia permitir, caso fosse bem feita, diluem-se muito rapidamente. Generalizando, a possibilidade ou a suspeita de erro e correspondente prejuízo, qualquer que seja o motivo, está sempre presente em sistemas complexos que implicam interdependência entre pessoas, ainda mais quando existem os constrangimentos à autonomia individual resultantes da necessidade de cooperação. Daí que processos como o da confiança, que podem atenuar os efeitos negativos do exercício do poder, por exemplo numa avaliação imperfeita, tenham despertado interesse pela margem de erro e pelos processo de aprendizagem e ajustamento sem rupturas relacionais que permitem.

Neste ponto da reflexão, a diferença eventual entre confiança interpessoal e confiança organizacional começa a tornar-se relevante. As ideias sobre a confiança interpessoal têm-se desenvolvido no pressuposto de uma relação livre e igualitária. No entanto, as relações no seio de uma organização não são desta natureza. Elas são transitórias e constrangidas por um conjunto de expectativas e de normas associadas aos papéis organizacionais que as partes numa relação assumem.

Pensemos na relação entre uma chefia de primeira linha e um subordinado: a relação entre ambas as pessoas é constrangida necessariamente pelos papéis que ambos desempenham. À chefia cabe, por hipótese, determinar a forma e o ritmo a que uma tarefa é executada e controlar se essa forma e ritmo são seguidos. Por sua vez, se estamos numa estrutura minimamente complexa verticalmente, esta chefia vai provavelmente ter de mostrar como a execução das suas tarefas seguiu definições da sua própria chefia. Este contexto de realização implica necessariamente constrangimentos quer ao nível dos comportamentos individuais da chefia e do subordinado, quer da forma como a sua relação se desenvolve. No limite, ela deixa de ter qualquer significado, se a dimensão de execução não existir. Como este exemplo mostra muito esquematicamente, em cada díade onde poderíamos tentar definir o processo da confiança está presente o resto da organização, quer através da cadeia de autoridade, quer através de normas, quer de qualquer outra maneira. Assim, a definição de 
confiança como a disponibilidade para se colocar numa situação de vulnerabilidade com base em expectativas positivas toma um significado diferente: vulnerabilidade e expectativas positivas definem-se face a um sistema organizacional, não limitado a uma pessoa individualmente considerada, com quem se pode ter a melhor das relações. Claro que podemos usar como referencial uma pessoa: num questionário, por exemplo, faremos bem em concretizar o melhor possível o contexto que avaliamos, digamos, a confiança sentida. Mas estaremos provavelmente sempre a mobilizar avaliações de processos contextualizados numa organização completa.

As implicações para a avaliação e medida da confiança organizacional são relevantes e vale a pena enunciar algumas delas. Em primeiro lugar, as relações onde estamos a medir a confiança são, como vimos, constrangidas. Ambas as partes desempenham papéis que reduzem as possibilidades de interacção aos modos aceitáveis na organização específica, o que elimina possibilidades de interacção que em contextos menos constrangidos permitiriam evoluções diferentes da relação numa díade. $\mathrm{Na}$ avaliação que as pessoas fazem da confiança que sentem num contexto organizacional, não só os comportamentos e interacções directas numa díade são relevantes mas também as outras dimensões organizacionais, como normas, procedimentos e formas institucionais de comunicação, que interferem na relação. Por exemplo, as regras formais para recorrer de uma avaliação de desempenho podem determinar se numa entrevista de avaliação há abertura e são partilhadas dificuldades na realização das tarefas ou se todo o exercício é puramente defensivo por parte de quem é avaliado. Uma implicação desta ideia é que o que sabemos sobre os processos "normais", ou seja, não organizacionais, de desenvolvimento da confiança não se aplica necessariamente ‘confiança organizacional.

Em segundo lugar, quando questionamos os indivíduos sobre dimensões destas relações, como a confiança, o processo de produção das suas respostas será igualmente constrangido pelos papéis organizacionais que assumem, o que as fará provavelmente diferentes das respostas que seriam dadas num contexto, por exemplo, mais privado ou mais íntimo. A comunicação, mesmo quando reduzida a um questionário, tem sempre uma dimensão pragmática. Por exemplo, pode ser desajustado num sistema organizacional específico, manifestar desconfiança na chefia, embora ela possa existir. Os resultados de uma manifestação pública, mesmo que anónima, de desconfiança face à chefia directa, podem não ser os mais desejáveis para quem responde a um 
questionário, ou para o seu grupo de referência. Não portanto impensável que as respostas sejam dadas com essas consequências em mente.

Em resumo, ainda que a confiança organizacional seja claramente uma dimensão das relações dentro da organização que é relevante investigar e medir, é essencial, tal como em qualquer outra avaliação psicológica, que o constructo a avaliar seja o mais claro possível e que a relação entre os procedimentos de avaliação e as medidas resultantes seja também ela clara.

\section{ESTUDO DO QUESTIONÁRIO DE CONFIANÇA ORGANIZACIONAL}

Sem entrar numa revisão exaustiva da literatura sobre confiança organizacional, um dos modelos teóricos mais citados a respeito da confiança organizacional é o de Mayer, Davis e Schoorman (1995). A sua popularidade vem-lhe de não só adiantar a definição de confiança já referida, como de definir explicitamente um modelo causal psicológico para a confiança. O modelo causal define os antecedentes da confiança como a avaliação que o sujeito focal que confia (trustor) faz da competência, benevolência e integridade da pessoa em quem confia (trustee), antecedentes esses cujos efeitos são moderados pela propensão para confiar do sujeito focal.

O objectivo do estudo é assim o de avaliar a capacidade de medida da confiança organizacional do modelo proposto por Mayer, Davis e Schoorman (1995) e operacionalizado em Mayer e Davis (1999) e Mayer e Gavin (2005).

Além desta definição explícita de um modelo causal, dois destes investigadores publicaram em 1999 um estudo da relação entre confiança organizacional e atitudes face à avaliação do desempenho (Mayer e Davis, 1999), em que publicaram também o instrumento usado nesta investigação. Este instrumento viria a ser retomado e refinado em estudos posteriores, nomeadamente o de Mayer e Gavin (2005) sobre a relação entre a confiança organizacional e a capacidade de atenção concentrada nas tarefas envolvidas nos postos de trabalho, em que a subescala de Confiança é mais desenvolvida.

\subsection{Descrição da escala}

O trabalho de Mayer e Gavin (2005) resultou numa escala destinada a suscitar respostas de pessoas numa relação de dependência hierárquica, utilizando como referente a chefia directa ou a administração de uma organização. A escala tem 35 itens, 
dividida em 5 subescalas (Em anexo apresenta-se a versão portuguesa, já com as nossas opções de definição do referente; Anexo 1):

Tabela 1 - Questionário de Confiança Organizacional

\begin{tabular}{ccl} 
Subescala & No $\mathbf{N}^{\mathbf{0}}$ itens & \multicolumn{1}{c}{ Constructo } \\
\hline Competência & 6 & $\begin{array}{l}\text { Avaliação da competência do referente na realização das } \\
\text { suas tarefas específicas. }\end{array}$ \\
\hline Benevolência & 5 & $\begin{array}{l}\text { Avaliação das intenções do referente em relação ao sujeito } \\
\text { focal. }\end{array}$ \\
\hline Integridade & 6 & $\begin{array}{l}\text { Avaliação do grau em que o comportamento do referente é } \\
\text { orientado por princípios e valores compreensíveis e } \\
\text { partilhados. }\end{array}$ \\
\hline Propensão para & 8 & $\begin{array}{l}\text { Propensão que o indivíduo focal tem para confiar nas } \\
\text { outras pessoas, num sentido geral, não restrito à } \\
\text { organização em que está. }\end{array}$ \\
\hline Confiança & 10 & $\begin{array}{l}\text { Disponibilidade para se colocar numa situação de } \\
\text { vulnerabilidade face ao referente, sem ter grande controlo } \\
\text { da situação. }\end{array}$ \\
\hline
\end{tabular}

\subsection{Adaptação da escala}

A escala foi traduzida do inglês e pré-testada numa amostra de conveniência de 6 pessoas, com as mesmas características da população alvo. Ou seja, pessoas que trabalhavam regularmente numa relação de dependência hierárquica. As reacções das pessoas aos itens foram registadas e comparadas, tendo sido modificada a formulação de alguns itens menos claros.

Optou-se por definir como referente a chefia directa, uma vez que os contextos a que prevíamos ter acesso eram muito variados em termos da distância entre os operadores directos e a gestão de topo da organização.

Realizámos uma análise factorial exploratória, com uma amostra de 580 pessoas, a trabalhar em 4 organizações diferentes, em que os itens apresentaram um padrão de saturação dos factores diferente do expectável: os itens da subescala de Benevolência e Integridade apareciam juntos no mesmo factor e os itens da subescala de Confiança com um padrão de saturação dos factores que sugeria uma estrutura bi-factorial. No 
entanto, como problemas semelhantes a estes dois já tinham sido identificados em investigações anteriores pelos autores originais, sem que isso invalidasse a utilização que fizeram da escala, e como não tínhamos claro que os problemas das dimensões da escala fossem os mesmos, optámos por prosseguir na recolha de dados com o mesmo instrumento.

\subsection{População}

A versão final foi aplicada a uma amostra de cerca de 1100 pessoas a trabalhar numa relação de dependência hierárquica, em 10 organizações diferentes, na sua maioria industriais, mas incluindo também alguns serviços.

\subsection{Procedimentos}

Os questionários foram passados de formas variadas. Nalguns casos, as pessoas preencheram-nos em casa, mas na maioria foram preenchidos no trabalho, em tempo e instalações disponibilizados para o efeito. Embora em cada caso a organização tivesse acesso aos resultados globais obtidos, a independência dos objectivos do estudo em relação à organização foi deixada clara e garantido o anonimato das respostas individuais.

\section{ANÁLISE DOS DADOS}

\section{Casos}

A base de dados foi examinada para averiguar a existência de observações extremas, tendo sido excluídos os outliers multivariados usando a distância de Mahalanobis e a de Cook $\left(\mathrm{d}_{(35 \text { g.l. })}^{2}>66.6\right.$ ou $\left.\mathrm{D}_{\text {Cook }}>0.0046\right)$. Excluíram-se também os casos com mais de $10 \%$ de valores em falta. A amostra ficou assim reduzida a 903 casos.

\section{Variáveis}

Grande parte das variáveis observadas (itens) apresenta distribuições assimétricas, mas como todos os coeficientes de assimetria com valores significativos são negativos, à excepção de um dos itens da subescala de Confiança, não efectuamos qualquer transformação sobre as variáveis. O mesmo se passou com os coeficientes de curtose, cujos valores significativos eram todos positivos, à excepção de dois outros itens da subescala de Confiança. Estes três itens foram excluídos antes da análise factorial 
confirmatória, ficando a escala de Confiança com 7 itens. O QCO ficou portanto reduzido a 32 itens.

Avaliou-se a consistência interna das subescalas bem como as suas intercorrelações e realizou-se um primeiro teste parcial de ajustamento do modelo

Figura 1: AFC modelo inicial

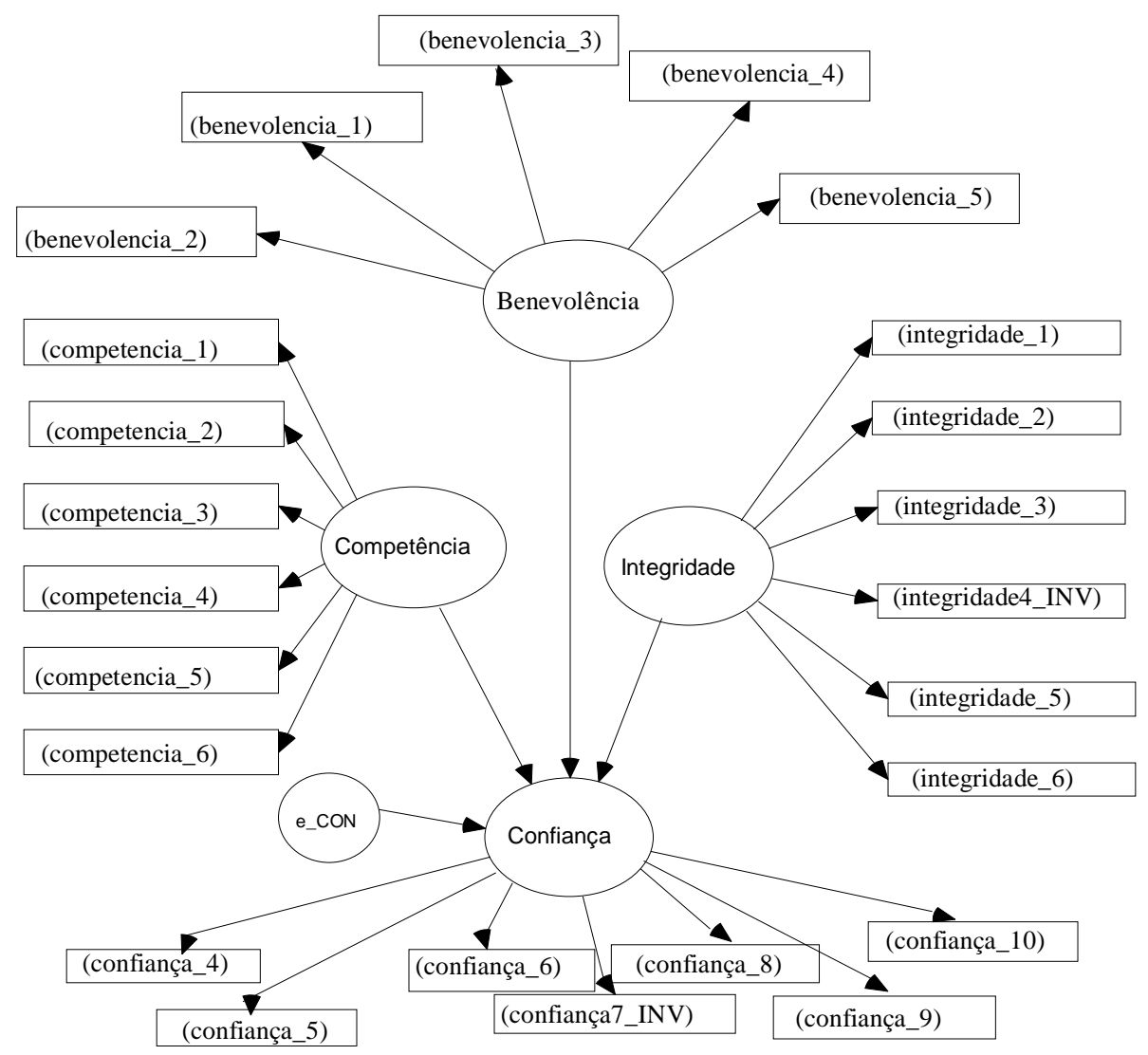

teórico aos dados recolhidos, através de modelização com equações estruturais (usando o software AMOS 17.0).

O modelo testado está descrito no diagrama da Erro! A origem da referência não foi encontrada.. Ausente deste modelo está a variável moderadora da relação entre preditores e Confiança (a Propensão para confiar). Esta ausência justifica-se em parte pela complexidade de que esta análise se revestiria e em parte porque os próprios autores do modelo não incluem as interacções com a variável moderadora quando avaliam quer a validade do modelo quer a sua interacção com outras variáveis (p.ex. Mayer e Davis, 1999, Mayer e Gavin, 2005). 


\section{RESULTADOS}

\subsection{Consistência interna e correlações}

A consistência interna variou bastante entre as subescalas, sendo o caso mais problemático o da subescala de Confiança, precisamente a variável dependente do modelo em estudo (Tabela 2).

Tabela 2: Subescalas do QCO

\begin{tabular}{|c|c|c|c|c|c|}
\hline & Média (d.p.) & $\begin{array}{c}\alpha \\
\text { Cronbach }\end{array}$ & 1 & 2 & 3 \\
\hline 1. Competência & $3.75(.72)$ & .93 & & & \\
\hline 2. Benevolência & $3.37(.76)$ & .90 & ,739" & & \\
\hline 3. Integridade & $3.42(.64)$ & .85 &, $745^{\prime \prime}$ & 807 & \\
\hline 4. Confiança & $3.64(.48)$ & .70 &, 509 & , 495 & , 575 \\
\hline
\end{tabular}

${ }^{* *} . p<0.01$ bicaudal

A matriz de correlações entre os valores nas subescalas não contém valores demasiado elevados, embora as correlações comparativamente mais baixas da Confiança com os seus preditores seja um pouco inesperada.

\subsection{Análise estrutural}

O modelo testado está representado na Erro! A origem da referência não foi encontrada.., correspondendo ao modelo proposto pelos autores, excepto os itens da subescala da Confiança retirados dada a sua distribuição. Por uma questão de economia de espaço, não estão representados os termos de erro das variáveis observadas.

Os indicadores de ajustamento deste modelo mostram um fraco ajustamento aos dados ( $\chi 2$ /graus de liberdade $=11.67 ; p<001 ; \mathrm{GFI}=.804 ; \mathrm{RMSEA}=.109$ ), pelo que optámos por explorar de onde vêm os maiores contributos para esta falta de confirmação do modelo de partida.

A análise dos índices de modificação fornecidos pelo programa e a análise de cada uma das subescalas separadamente sugeriram algumas modificações ao modelo inicial. Parte delas são interpretáveis como modificações directas do modelo teórico original, outras são provavelmente limitações da versão do instrumento usado.

\subsection{Modificações ao modelo original}

Um conjunto de modificações que alterou significativamente o ajuste do modelo aos dados foi a inclusão no modelo de relações entre os preditores da Confiança, nomeadamente a relação entre a Benevolência e a Integridade $\left(\Delta \chi_{(1)}^{2}=976.1, \mathrm{p}=.000\right)$. Optamos por esta alteração, porque são duas dimensões relacionadas com a interacção 
directa com a chefia. Por outro lado, as acções de uma chefia determinadas por um conjunto de normas e de princípios, e que portanto serão previsíveis e universais podem, num contexto imprevisível, ser percebidas como benevolentes. Se este efeito puder ser confirmado, será interessante compreender em que contextos ele é mais visível.

Uma segunda modificação importante para o ajustamento do modelo aos dados foi a inclusão no modelo da relação entre Competência e Integridade (em relação ao modelo original, $\left.\Delta \chi_{(2)}^{2}=1131.2, \mathrm{p}=.000\right)$.

Duas modificações finais trouxeram o modelo para níveis aceitáveis de ajustamento $\left(\chi^{2} /\right.$ graus de liberdade $\left.=6.7 ; \mathrm{GFI}=.88 ; \mathrm{RMSEA}=.080\right)$ embora não muito bons. Ambas implicaram a introdução no modelo de covariâncias entre factores de erro dos itens, o que sugere que o instrumento deverá ser melhorado.

Com este modelo final, os coeficientes normalizados de regressão da confiança para os preditores são de .216 para a Competência, de .582 para a Integridade e de -.051 (não significativo) para a Benevolência.

\section{BALANÇO DO MODELO: MEDIDAS E REGRESSÃO}

\subsection{Medida de Confiança}

O ajustamento marginal do modelo aos dados evidencia vários problemas com este modelo. Levando em consideração os níveis de ajustamento do modelo aos dados, bem como a informação dada pela análise da consistência interna das subescalas, a maior limitação deste modelo parece estar na medida de confiança. A consistência interna baixa, já identificada no estudo de Mayer e Gavin (2005), indica um padrão de respostas pouco consistente, sugerindo a necessidade de desenvolvimento conceptual que sustente um desenvolvimento da estratégia de medida. Mayer e Gavin (2005:879) optaram por enquadrar esta questão como um problema de dimensionalidade (o constructo Confiança teria mais dimensões do que se esperava) e distinguiram entre a atitude geral de confiar e a intenção do sujeito focal de se envolver em comportamentos que implicam confiança. A questão, no entanto, talvez tenha que se colocar ainda a montante desta questão. Quando questionamos as pessoas a partir do seu papel organizacional as respostas são também dadas a partir desse papel, ou seja, são constrangidas pelos mesmos processos que constrangem os comportamentos individuais na organização.

A vulnerabilidade implicada no processo da confiança organizacional não é um processo a que as pessoas sejam indiferentes. Embora com diferenças individuais, cada 
pessoa adopta estratégias para lidar com a incerteza associada a esta vulnerabilidade. Estas estratégias, para serem estratégicas, implicam gerir a informação que sobre elas é fornecida a outrem. Ora, quando questionamos sobre a confiança esperamos que as pessoas nos digam qual é a sua estratégia: simplificando, confia ou não confia. Esta expectativa pode ser completamente desajustada face à estratégia que a pessoa escolheu para lidar com a incerteza associada à sua vulnerabilidade. Este desajustamento pode ser uma explicação alternativa para o padrão mais errático de respostas aos itens da subescala Confiança.

\subsection{Relação entre as variáveis}

Por outro lado, o comportamento dos preditores da Confiança sugere que o processo cognitivo implicado não é bem descrito pelo modelo proposto.

Por um lado, a necessidade de incluir no modelo associações entre os preditores mostra que eles não são independentes entre si, um problema já reconhecido pelos proponentes do modelo a propósito da relação entre Benevolência e Integridade. Neste artigo, no entanto, os autores relacionam esta associação com o efeito do tempo no desenvolvimento da confiança. Em fases iniciais da relação, as duas dimensões sobrepõem-se porque o sujeito focal ainda não teve tempo para recolher informações sobre a benevolência da chefia, enquanto a integridade requer menos tempo para ser avaliada (Schoorman, Mayer e Davis, 2007:346). No entanto, a amostra do presente estudo varia muito em termos de antiguidade, sendo o escalão médio e antiguidade o escalão entre 5 e 10 anos de antiguidade na organização.

Por outro lado, o coeficiente de regressão não significativo da Confiança para a Benevolência, indicando que toda a relação da Benevolência com a Confiança se faz através da influência da Integridade, sugere que esta dimensão não é relevante no modelo, uma conclusão importante, face ao modelo original, a avaliar com algum cuidado.

A conclusão provisória que este balanço nos sugere é o de que é essencial aprofundar os conceitos envolvidos neste modelo de confiança organizacional, bem como as estratégias para a sua medida. Começando pelo preditores da confiança, no caso da Competência podemos considerar que estamos em presença de uma medida aceitável, quer pela análise da sua consistência interna quer pela análise factorial. Os outros dois preditores da confiança apresentam um padrão menos claro. Talvez a benevolência e a integridade não sejam dimensões adequadas para avaliar a relação 
entre subordinados e chefias, ou talvez a medida desenvolvida não seja adequada nos contextos que estudamos. Quanto à confiança, parece ser a variável que mais claramente requer uma reavaliação quer do constructo, por hipótese tentando inserir considerações mais estratégicas na sua definição, quer da estratégia de medida.

\section{REFERÊNCIAS BIBLIOGRÁFICAS}

Mayer, R. C., \& Davis, J. H. (1999). The effect of the performance appraisal system on trust for management: a field quasi-experiment. Journal of Applied Psychology, 84, 123-136.

Mayer, R. C., \& Gavin, M. B. (2005). Trust in management and performance: who minds the shop while the employees watch the boss? Academy of Management Journal , (48)5, 874-888.

Mayer, R. C., Davis, J. H., \& Schoorman, F. D. (1995). An integrative model of organizational trust. Academy of Management Review , 20, 709-734.

Rousseau, D., Sitkin, S. B., Burt, R. S., \& Camerer, C. (1998). Not so different after all: A cross-discipline view of trust. The Academy of Management Review , (23)3, 393.

Schoorman, F. D., Mayer, R. C., \& Davis, J. H. (2007). An integrative model of organizational trust: past, present and future. Academy of Management Review , (32)2, 344-354. 


\section{ANEXO 1: QCO}

1. A minha chefia é muito competente na realização do seu trabalho.

2. A minha chefia é conhecida por ser bem sucedido nas tarefas que tenta fazer.

3. A minha chefia conhece em profundidade o trabalho que precisa de ser feito.

4. Sinto-me muito confiante nas capacidades da minha chefia.

5. A minha chefia tem capacidades especializadas que podem aumentar o nosso desempenho

6. A minha chefia é muito qualificada.

7. A minha chefia preocupa-se muito com o meu bem estar.

8. As minhas necessidades e desejos são muito importantes para a minha chefia

9. A minha chefia não faria nada para me prejudicar intencionalmente.

10. A minha chefia presta realmente atenção ao que é importante para mim

11. A minha chefia alterará o seu modo de agir habitual para me ajudar.

12. A minha chefia tem um forte sentido de justiça.

13. Nunca tenho que me preocupar se a minha chefia irá cumprir a sua palavra

14. A minha chefia esforça-se por ser justa nas suas relações com os outros.

15. As acções e os comportamentos da minha chefia não são muito consistentes.

16. Eu partilho dos princípios da minha chefia.

17. O comportamento da minha chefia parece ser orientado por bons princípios.

18. Devemos ser muito cautelosos com pessoas desconhecidas.

19. A maioria dos profissionais diz a verdade sobre os limites do seu próprio conhecimento.

20. A maioria das pessoas cumpre aquilo que diz.

21. Nos dias que correm, devemos estar alerta ou é provável que alguém se aproveite de nós.

22. A maioria dos vendedores é honesta na apresentação dos seus produtos.

23. A maioria das pessoas que conserta coisas não irá cobrar dinheiro a mais aos clientes que não percebem dessa especialidade.

24. A maioria das pessoas responde honestamente aos inquéritos de opinião pública.

25. A maioria dos adultos é competente no seu trabalho

26. Se eu pudesse, não deixaria que a minha chefia tivesse qualquer influência sobre os assuntos que são importantes para mim.

27. Estaria disposto a que a minha chefia exercesse total controlo sobre o meu futuro nesta empresa.

28. Realmente gostaria de saber de uma boa maneira de ter a minha chefia "debaixo de olho".

29. Sentir-me-ia à vontade para entregar a minha chefia uma tarefa ou um problema crítico para mim, mesmo que eu não pudesse verificar as suas acções.

30. Diria os erros que cometi na realização do meu trabalho à minha chefia, mesmo que isso manchasse a minha reputação.

31. Partilharia a minha opinião sobre assuntos "sensíveis" com a minha chefia mesmo que esta fosse impopular.

32. Estou receoso do que a minha chefia poderá fazer-me no meu local de trabalho.

33. Se a minha chefia me perguntasse porque é que aconteceu determinado problema, falaria livremente mesmo que eu tivesse também alguma culpa.

34. Se alguém questionasse os motivos da minha chefia, eu dar-lhe-ia o beneficio da dúvida.

35. Se a minha chefia me perguntasse alguma coisa, responderia sem me questionar se essas informações poderiam ser utilizadas contra mim. 